www.jmscr.igmpublication.org

Impact Factor 5.84

Index Copernicus Value: 71.58

ISSN (e)-2347-176x ISSN (p) 2455-0450

crossref DOI: _https://dx.doi.org/10.18535/jmscr/v5i11.93

Journal Of Medical Science And Clinical Research

Original Article

\title{
Clinical and Etiological Profile, Outcome and Prognostic Factors in Children less than 12 years with Empyema Thoracis Attending an Urban Referral Centre
}

Corresponding Author

Arul Prasadh

Assistant Professor, Department of Pediatrics, Kanyakumari Government Medical College

\begin{abstract}
Background: Empyema thoracis, an accumulation of pus in the pleural space is most often associated with pneumonia due to Streptococcus pneumoniae, although Staphylococcus aureus is most common in developing nations and in post-traumatic empyema. Empyema is most frequently encountered in infants and preschool children. It

occurs in $5-10 \%$ of children with bacterial pneumonia. This study was conducted to find the etiological profile of empyema in our setup, and factors that influence the outcome of empyema. This may help in effective management of empyema thoracis in future.

Methodology: All the children 1 month to 12 years old diagnosed as having empyema thoracis during the period June 2003 - October 2004, attending our hospital and willing to adhere to our study protocol were enrolled in our study.

Detailed history was elicited from the patient and a thorough clinical examination done. Diagnosis was confirmed with proper investigations. Pleural aspiration was done and pleural aspirate subjected to biochemical examination, gram staining was done and sample was sent for pus culture and sensitivity.

Complete blood count, X-ray chest, ultrasonogram of chest if needed, Mantoux were done. Blood was also sent for blood culture. Tube thoracostomy was done in all patients confirmed to have empyema thoracis. Inter Costal Drainage Tube of adequate size was inserted to ensure proper and complete drainage.

Results: In our study we find that gram positive organisms were isolated in $49 \%$ of culture proven cases and gram negative organisms were isolated from $51 \%$ of culture proven empyema thoracis cases.

Locality wise distribution helps us to compare the adequacy of treatment in urban and rural areas.

$70 \%$ of children presenting with empyema thoracis had undernutrition. Duration of illness also significantly affect the outcome. When the duration of illness is $>7$ days prior to insertion of ICD tube chances are high that the empyema would have progressed beyond stage I and empyema is in stage II or III.

Conclusion: Gram negative organisms were more isolated from the children with empyema thoracis.empyema thoracis is more common among undernourished children.Duration of illness also significantly affect outcome.
\end{abstract}




\section{Introduction}

Empyema thoracis, an accumulation of pus in the pleural space is most often associated with pneumonia due to Streptococcus pneumoniae, although Staphylococcus aureus is most common in developing nations and in post-traumatic empyema. The relative incidence of Haemophilus influenza empyema has decreased since the introduction of $\mathrm{Hib}$ vaccination. Group A streptococcus, gram negative organisms, tuberculosis, fungi and malignancy are less common causes. Empyema is most frequently encountered in infants and preschool children. It occurs in $5-10 \%$ of children with bacterial pneumonia. The disease may also be produced by rupture of a lung abscess into the pleural space, by contamination introduced from trauma or thoracic surgery or rarely by mediastinitis or the extension of intra - abdominal abscesses. ${ }^{1}$

\section{Aim of the Study \\ To study}

1. The causative organism in empyema thoracis in our institute.

2. The factors associated with poor prognosis in empyema thoracis in children.

\section{Subjects and Methods}

Study design- Descriptive/Nested Case Control Study.

\section{Study place- $\mathrm{ICH} \& \mathrm{HC}$}

Study period- June 2003 - October 2004

Study population - Children 1 month to 12 years diagnosed as having empyema thoracis.

Exclusion criteria- Patients and physicians not willing to adhere to our study protocol.

Sample size - All children 1 month to 12 years diagnosed as having empyema thoracis who satisfy above criteria.

\section{Manoeuvre}

All the children 1 month to 12 years old diagnosed as having empyema thoracis during the period June 2003 - October 2004, attending our hospital and willing to adhere to our study protocol were enrolled in our study.

Detailed history was elicited from the patient and a thorough clinical examination done. Diagnosis was confirmed with proper investigations. Pleural aspiration was done and pleural aspirate subjected to biochemical examination, gram staining was done and sample was sent for pus culture and sensitivity.

Complete blood count, X-ray chest, ultrasonogram of chest if needed, Mantoux were done. Blood was also sent for blood culture. Tube thoracostomy was done in all patients confirmed to have empyema thoracis. Inter Costal Drainage Tube of adequate size was inserted to ensure proper and complete drainage.

\section{Statistical Analysis}

a) The proportion of various etiological agents and outcome were arrived.

b) To study the prognostic factors, odds ratio with 95\% confidence interval was arrived at for each risk factor byunivariate analysis by constructing a $2 \times 2$ table. To adjust for confounding variables, adjusted odds ratio with 95\% confidence interval was arrived at by multivariate anaylsis for the signifant risk factors with univariate anaylsis. $\mathrm{P}$ value $<0.05$ will be considered for statistical significance.

\section{Observation}

Total number of empyema thorocis patients during the study period : 106

No : Children who recovered without complications : 60 (Control) No : Children who recovered with complication and / or decortications $\quad: 32$ Death : 436 (cases) Organisms were grown in pus culture and / or blood culture in 37 cases (36\%) Organisms grown in our institute were

\section{Table - 1}

\begin{tabular}{|l|c|}
\hline Staphylococcus aureus & 15 \\
\hline Klebsiella & 13 \\
\hline Pseudomonas & 5 \\
\hline Pneumococci & 3 \\
\hline E. coli & 1 \\
\hline
\end{tabular}




\section{Clinical Profile}

Table - 2

\begin{tabular}{|l|c|c|}
\hline Symptoms & No. & $\%$ \\
\hline Fever & 103 & $97 \%$ \\
\hline Cough & 89 & $84 \%$ \\
\hline Difficulty in breathing & 85 & $80 \%$ \\
\hline Vomiting & 14 & $13 \%$ \\
\hline Abdominal distension & 12 & $11 \%$ \\
\hline Chest Pain & 7 & $6.5 \%$ \\
\hline
\end{tabular}

Thus we find that fever, cough, difficulty in breathing are the predominant symptoms, while $13 \%$ of patients had vomiting and $11 \%$ of patients had abdominal distension (Table 2). Empyema was right sided in 62 children $(58.5 \%)$ and left sided in 44 children (41.5\%). $80 \%$ of the children has a total counts $>10,000$.

\section{Age Pattern of Cases and Control}

Table - 3

\begin{tabular}{|l|c|c|c|}
\hline Age months & Case (\%) & Control (\%) & Total \\
\hline 0-12 months & $7(19.4 \%)$ & $26(37.1 \%)$ & $33(31.1 \%)$ \\
\hline $13-36$ months & $12(33.3 \%)$ & $13(18.6 \%)$ & $25(23.6 \%)$ \\
\hline $37-60$ months & $8(22.2 \%)$ & $19(27.1 \%)$ & $27(25.5 \%)$ \\
\hline $\begin{array}{l}61-120 \\
\text { months }\end{array}$ & $9(25 \%)$ & $12(17.1 \%)$ & $21(19.8 \%)$ \\
\hline
\end{tabular}

In our study, children less than 12 months constitute $31 \%$ of total empyema cases. Children less than 36 months account for 55\% of empyema thoracis cases while children less than 5 years constitute almost $80 \%$ and only $20 \%$ of empyema thoracis cases is in children more than 5 years old (Table 3).

\section{Sex Wise Distribution Of Cases And Controls}

\section{Table -4}

\begin{tabular}{|l|c|c|c|}
\hline & Case & Control & Total \\
\hline Male & $21(58.3 \%)$ & $36(51.4 \%)$ & $57(53.8 \%)$ \\
\hline Female & $15(41.7 \%)$ & $34(48.6 \%)$ & $49(46.2 \%)$ \\
\hline
\end{tabular}

There is a slight preponderance of males in our study.

Males constitute $54 \%$ of empyema thoracis cases Female account for $46 \%$ of empyema thoracis cases (Table 4).
Locality Wise Distribution of Cases and Controls

Table - 5

\begin{tabular}{|l|c|c|c|}
\hline & Case & Control & Total \\
\hline Chennai & $21(58.3 \%)$ & $30(42.86 \%)$ & $51(48.1 \%)$ \\
\hline $\begin{array}{l}\text { TN outside } \\
\text { chennai }\end{array}$ & $7(19.4 \%)$ & $22(31.4 \%)$ & $29(27.4 \%)$ \\
\hline Other States & $8(22.2 \%)$ & $18(25.7 \%)$ & $26(24.5 \%)$ \\
\hline
\end{tabular}

About $50 \%$ of patients are from Chennai while $25 \%$ of cases were from other states. $25 \%$ of patients were from rural areas of Tamil Nadu (Table 5). Locality wise distribution helps us to study the referral pattern of our hospital and also comparing adequacy of treatment in urban vs rural setup.

\section{Nutritional Status Wise Distribution}

Table - 6

\begin{tabular}{|l|c|c|c|}
\hline $\begin{array}{c}\text { Nutritional } \\
\text { status }\end{array}$ & Case & Control & Total \\
\hline Normal & $\begin{array}{c}6 \\
(16.7 \%)\end{array}$ & $\begin{array}{c}29 \\
(41.4 \%)\end{array}$ & $\begin{array}{c}35 \\
(33 \%)\end{array}$ \\
\hline Grade I PEM & $\begin{array}{c}14 \\
(38.9 \%)\end{array}$ & $\begin{array}{c}17 \\
(24.3 \%)\end{array}$ & $\begin{array}{c}31 \\
(29.2 \%)\end{array}$ \\
\hline Grade II PEM & 9 & 10 & 19 \\
$(25 \%)$ & 7 & $14.3 \%)$ & $(18 \%)$ \\
\hline Grade III PEM & $\begin{array}{c}14 \\
(19.4 \%)\end{array}$ & $\begin{array}{c}21 \\
(20 \%)\end{array}$ \\
\hline
\end{tabular}

$33 \%$ of the patients were nutritionally normal while the rest $67 \%$ were undernourished. Grade I PEM was present in $30 \%$ of patients. Grade II PEM was seen in $18 \%$ of patients. Grade III PEM was seen in $20 \%$ of patients. None of the patients were of Grade IV PEM (Table 6).

\section{Statistical Analysis}

1) Comparison Of Risk Factors Among Cases And

2) Controls By Univariate Analysis

\section{Nutritional Status}

Table - 7

\begin{tabular}{|l|c|c|}
\hline & Cases & Control \\
\hline Undernutrition + & 30 & 41 \\
\hline Undernutrition - & 6 & 29 \\
\hline
\end{tabular}




\section{JMSCR Vol||05||Issue||11||Page 30363-30369||November}

Odds Ratio

$=\quad 3.537$ with

95\% Confidence Interval

$(1.305-9.587)$

Thus we find that undernutrition is significantly associated with cases as per univariate analysis. Further multivariate analysis is required for adjusting for confounding variables.

Thus we find that the odds of a child being undernourished is 3.5 times more common among children who go for complication / decortication when compared to children who recover without complication.

\section{Duration Of Illness Prior To Icd Insertion}

Table -8

\begin{tabular}{|l|c|c|}
\hline & Case & Control \\
\hline$>7$ days & 21 & 23 \\
\hline$\geq 7$ days & 15 & 45 \\
\hline
\end{tabular}

Odds Ratio $=$

2.739 with a

95\% Confidence Intervel of $1.193-6.291$

which is also significant by univariate analysis. Further multivariate analysis is required for adjusting for confounding variables.

Thus we find that the odds of a child presenting after 7 days of illness is 2.7 times more common among children who go for complication / decortication when compared to children who recover without complication.

\section{Previous Treatment}

Table - 9

\begin{tabular}{|l|c|c|}
\hline & Case & Control \\
\hline Previous treatment + & 15 & 14 \\
\hline Previous treatment - & 21 & 56 \\
\hline
\end{tabular}

Odds Ratio $-2.857$

95\% Confidence Interval of $1.18-6.92$

Thus we find that history of previous treatment is significant by univariate analysis. The odds of a child having been treated previously is 2.8 times more common among children who go for complication / decortication when compared to children who recover without complication.

\section{Congenital Anamoly and Associatedillness}

Table - 10

\begin{tabular}{|l|c|c|}
\hline & Cases & Control \\
\hline $\begin{array}{l}\text { Congenital anamoly \& } \\
\text { associated illness + }\end{array}$ & 5 & 3 \\
\hline $\begin{array}{l}\text { Congenital anarnoly \& } \\
\text { associated illness - }\end{array}$ & 31 & 67 \\
\hline
\end{tabular}

Odds Ratio - 3.602

95\% Confidence Interval of 0.809 - 16.037

\section{Comparing Other Factors Sex of the Child}

Table - 11

\begin{tabular}{|l|c|c|}
\hline & Cases & Control \\
\hline Male & 21 & 36 \\
\hline Female & 15 & 34 \\
\hline
\end{tabular}

Odds Ratio 1.32

95\% Confidence Interval of $0.587 \quad-2.977$

\section{Micro Organism}

Table - 12

\begin{tabular}{|l|c|c|}
\hline & Cases & Control \\
\hline Organism grown & 16 & 21 \\
\hline No organism grown & 20 & 49 \\
\hline
\end{tabular}

Odds Ratio - 1.867

95\% Confidence Interval of $0.812-4.293$

\section{Comparing Individual Micro Organism}

Table - 13

\begin{tabular}{|l|c|c|c|}
\hline Organism & Case & Control & OR \\
\hline Klebsiella & 7 & 6 & $\begin{array}{c}1.8(0.556- \\
5.822)\end{array}$ \\
\hline Staph.aureus & 10 & 5 & $\begin{array}{c}0.968(0.304- \\
3.08)\end{array}$ \\
\hline Pseudomonas & 2 & 3 & $5(0.478-$ \\
& & & $18.8)$ \\
\hline Pneumococci & 1 & 2 & $\begin{array}{c}4.06(0.355- \\
46.35)\end{array}$ \\
& & &
\end{tabular}

We find that none of the organism is significantly associated with poor prognosis.

\section{Locality of the Child}

Table - 14

\begin{tabular}{|l|c|c|}
\hline & Cases & Control \\
\hline Urban & 21 & 30 \\
\hline Rural & 15 & 40 \\
\hline
\end{tabular}

Odds Ratio - 1.867

95\% Confidence Interval of $0.827-4.214$ 
Age of the Child

Table - 15

\begin{tabular}{|l|c|c|}
\hline & Cases & Control \\
\hline Older children & 29 & 44 \\
\hline Infant & 7 & 26 \\
\hline
\end{tabular}

Odds Ratio - 2.448

95\% Confidence Interval of $0.94-6.376$

COMPARING DIFFERENT AGE GROUPS

Table - 16

\begin{tabular}{|l|c|c|c|}
\hline Age & Case & Control & OR \\
\hline $0-12 \mathrm{mo}$ & 7 & 26 & $0.408(0.157-1.064)$ \\
\hline $13-36 \mathrm{mo}$ & 12 & 13 & $2.192(0.875-5.49)$ \\
\hline $37-60 \mathrm{mo}$ & 8 & 19 & $0.767(0.298-1.975)$ \\
\hline $61-120 \mathrm{mo}$ & 9 & 12 & $1.611(0.606-4.28$ \\
\hline
\end{tabular}

Thus by univariate analysis, we find that none of the risk factors except nutritional status, duration of illness prior to ICD insertion, history of previous treatment is significantly associated with poor prognosis in empyema thoracis.

\section{Multivariate Analysis}

Multivariate analysis was done on the following variables

Age

Sex

Duration of illness

Previous treatment

Nutritional category.

Table -17

\begin{tabular}{|l|c|c|c|c|}
\hline & B & S.E & Wald & Sig. \\
\hline Age & 0.011 & 0.007 & 2.628 & 0.105 \\
\hline Male Sex & 0.384 & 0.461 & 0.694 & 0.405 \\
\hline $\begin{array}{l}\text { Duration of Illness } \\
\text { 7 days }\end{array}$ & 0.656 & 0.485 & 1.829 & 0.176 \\
\hline Previous treatment & 1.206 & 0.529 & 5.189 & 0.023 \\
\hline Undernutrition & -1.455 & 0.572 & 6.479 & 0.011 \\
\hline
\end{tabular}

$\mathrm{X}^{2}$ value $=20.144$

Nagelkerke R Square value $=0.240$

By Chi-square it was found that these factors have a significant association with the outcome. By
Nagelkerke R square value we find that these risk factors contribute $24 \%$ to the outcome.

Thus we find that history of previous treatment and undernutrition are significantly associated with poor outcome. Duration of illness $>7$ days though significant by univariate analysis did not achieve statistical significance in multivariate analysis (Table 17).

\section{Discussion}

106 children of empyema thoracis who attended our institute were included in our study. 103 children had fever (97\%), 89 children had cough (84\%), 85 children had difficulty in breathing (80\%), 12 children had abdominal distension (1 1\%) 7 children had chest pain $(6.5 \%)$. Beg et $\mathrm{a}^{24}$. have found that cough was found in $98 \%$ of children with empyema thoracis, fever in $95 \%$ of children with empyema. Breathlessness in $85 \%$ and chest pain in $83 \%$ Ghosh et $1^{23}$ have found that abdominal distension is present in $43 \%$ of children.

In our study we find that the empyema thoracis was right sided in 62 children $(58.5 \%)$ There was a mild male preponderance. Males constitute 54\% of total cases and children less than 3 years constitute $55 \%$ of the total empyema thoracis cases Ghosh et a123 has found that the empyema is right sided in $61 \%$ of cases, males constitute $65 \%$ and children $<2$ years constitute $70 \% .80 \%$ of children in our study had total count more than 10,000 while other study in the literature had total count more than 10,000 in $94 \%$ of empyema thoracis cases ${ }^{21}$. In several studies done so far organism isolation rate range from $10 \%{ }^{11}$ to $50 \%{ }^{27}$. In our study, organisms were isolated from 37 cases $(35 \%)$ which is fairly good. Previous antibiotic therapy outside could have decreased the organism isolation rate.

Though there are literatures saying gram + organism are the most common' in empyema thoracis, there are a few Indian studies which find that gram - organism are isolated in $84 \%$ of culture proven cases of empyema thoracis ${ }^{12}$. In our study we find that gram positive organisms 
were isolated in $49 \%$ of culture proven cases and gram negative organisms were isolated from $51 \%$ of culture proven empyema thoracis cases.

In locality wise distribution of empyema thoracis cases we find that about $50 \%$ of patients are from chennai which is to be expected. While a $25 \%$ of cases were from rural Tamilnadu and another 25\% were from Andra Pradesh. Locality wise distribution helps us to compare the adequacy of treatment in urban and rural areas. Only 30\% of children presenting with empyema thoracis were of normal nutrition. $70 \%$ had undernutrition which is higher than the prevailing undernutrition in the community. This could be due to the referral pattern of our hospital and also also as malnutrition predisposes to infection.

When all the risk factor were subjected to univariate analysis we found that Undernutrition OR 3.537 95\% CI (1.305 - 9.387)

Duration of illness > 7 day - OR $2.73995 \%$ CI $(1.193-6.291)$

History of Previous treatment - OR 2.857 95\% CI (1.18 - 6.92) were significantly associated with poor outcome in the from of complication $I$ death / decortication in empyema thoracis.

Undernutrition in these children predispose them to infection. Most of these undernutrition is due to nutritional deficit due to poor socio economic status of their parents and they usually get medical help late when the empyema would have progressed from stage I to stage II or Stage 111.

Duration of illness also significantly affect the outcome. When the duration of illness is $>7$ days prior to insertion of ICD tube chances are high that the empyema would have progressed beyond stage I and empyema is in stage II or III.

History previous treatment also affect the outcome $^{28}$ as most of the children who get treated outside are partially treated and no drainage is done. In these partially treated children, symptoms are masked and they get proper medical care quiet late when the empyema thoracis would have progressed to later stages.

The other risk factor like age group, associated congenital anamolies underlying illness, specific organisms were not significantly associated with poor outcome. While there are few studies which say staphylococci, pneurnococci are more prone to go for decortications (Mandal et al), ${ }^{18}$ our study could not established such an association.

When these risk factors were subjected to multivariate analysis by Logistic regression method we found that Malnutrition with a $p$ value of 0.011 History of previous treatment with a $p$ value of 0.023 were independently associated with poor outcome and these risk factor contribute $24 \%$ to the outcome.

\section{Bibliography}

1. Glenna B Winnie 'Empyema' in the Nelson Textbook of Pediatrics, 17" Edition, ed: Behrman. Kliegman. Jenson. Elsevier. 1462, 1463.

2. Chambers, Henry F. " Infectious Diseases : Bacterial and chlamydial". In current medical diagnosis and Treatment, $37^{\text {th }}$ ed. Ed Stephen McPhee et al stamford : Appleton and Lange, 1997.

3. Peter H. Michelson, Assistant Professor, Department of Paediatrics, Children Hospital of Pittsburg, University of Pittsburg - e Medicine.

4. Whyte, Richard I. ' Pleural effusion and Empyema Thoracis' In Conns Current Therapy 1996, ed. Robert E.Rake1, Philadelphia : W.B. Saunders Co : 1996.

5. Bryant RE et al. Pleural empyema. Clin Infect Dis 1996 May; 22 (5) : 747 - 762.

6. 'Thoracostomy Tube Drainage'. In the Merck Mancial of Diagnosis and Therapy, $16^{\text {th }} 1992$.

7. Rodolfa Majluf, Children Hospital, Buenos Aires, Argentina.

8. S.C. Sit et al. 'Urokinase in the treatment of Childhood Empyema'. Thorax 2003; 58 : $93-94$

9. Gupta SK et al. Indian J Chest Dis Allied Sci. 1989 Jan - Mar; 31 (1) : 15 - 20. 
10. Athanassiadi $\mathrm{K}$ et al. Thoracic condiovascular surgery 2003 Dec; 51 (6) : $338-341$.

11. Hilliard et al. Arch Dis Child. 2003 Oct; 88 (10) : 915 - 917.

12. Anstadt et al. Arn.J.Med. Sci. 2003 July ; 326 (1) : 9 - 14.

13. Huang FL et al. J. Microbiol Immunolo Infect. 2002 June; 35 (2) : 115 - 120.

14. Carey JA et al. Arch Dis Child. 1998 Dec; 79 (6) : $510-513$.

15. Mandal et al. Ann. Thorac. Surg. 1998 Nov ; 66 (5) : 1782 -1786.

16. Chan W et al. J Pediatr Surg. 1997 June; 32 (6) : 870 - 872.

17. Le Mense GP et al. Chest. 1995 June; 107 (6) : 1532 - 1537.

18. Maziah W et al. J. Trop Pediatr. 1995 June; 41 (3) : 185 - 188.

19. Kennedy AS et al. Arch Surg. 1991 Oct; $126(10)$ : 1287 - 1291.

20. Ghosh S et al. J. Indian Med Assoc. 1990 Jul; 88 (7) : $189-190$.

21. Beg MH et al. Ann Trop Paediatr. 1987 Jun; 7 (2) : 109 - 112.

22. Wehr CJ, Adkins RB Jr. South Med J. 1986 Feb;79(2): 171-176.

23. Asindi AA, Efem SE, Asuquo ME. East Afi Med J. 1992 Feb;69(2):78-82.

24. Chu MW et al. Can J Surgery 2001. Aug; 44 (4) : 284 - 288.

25. Cham CW et al. Thorax 1993 Sep; 48 (4) : 925 - 927.

26. Le Mense GP et al. Chest. 1995 June; 107 (6) : 1532 - 1537.

27. Maziah W et al. J. Trop Pediatr. 1995 June; 41 (3) : 185 - 188.

28. Kennedy AS et al. Arch Surg. 1991 Oct; 126 (10) : 1287 - 1291. 